\title{
Selective Innervation of Retinorecipient Brainstem Nuclei by Retinal Ganglion Cell Axons Regenerating through Peripheral Nerve Grafts in Adult Rats
}

\author{
Marcelino Avilés-Trigueros, ${ }^{1}$ Yves Sauvé, ${ }^{2}$ Raymond D. Lund, ${ }^{2}$ and Manuel Vidal-Sanz ${ }^{1}$ \\ ${ }^{1}$ Laboratorio de Oftalmología Experimental, Departamento de Oftalmología, Facultad de Medicina, Universidad de Murcia, \\ E-30100 Espinardo, Murcia, Spain, and 2Neural Transplant Program, Department of Pathology, Institute of \\ Ophthalmology, London EC1V 9EL, UK
}

\begin{abstract}
The pattern of axonal regeneration, specificity of reinnervation, and terminal arborization in the brainstem by axotomized retinal ganglion cell axons was studied in rats with peripheral nerve grafts linking the retina with ipsilateral regions of the brainstem, including dorsal and lateral aspects of the diencephalon and lateral aspect of the superior colliculus. Four to 13 months later, regenerated retinal projections were traced using intraocular injection of cholera toxin B subunit. In approximately one-third of the animals, regenerated retinal axons extended into the brainstem for distances of up to $6 \mathrm{~mm}$. Although axons followed different patterns of ingrowth depending on their site of entry to the brainstem, within the pretectum, they innervated preferentially the nucleus of the optic tract and the olivary pretectal nucleus in which they formed two types of terminal arbors. Within the superior colliculus, axons extended laterally
\end{abstract}

Axons of the CNS do not normally regenerate after injury, but a range of studies has shown that axonal regeneration is possible under specific experimental conditions, such as placing at the site of lesion a segment of peripheral nerve (David and Aguayo, 1981), Schwann cells (Xu et al., 1999), olfactory ensheathing cells (Li et al., 1997), activated macrophages (Lazarov-Spiegler et al., 1996, 1998), introducing trophic factors (Cheng et al., 1996; Menei et al., 1998) or antibodies against growth-inhibitory molecules present in the mature brain (Schnell and Schwab, 1990; Z'Graggen et al., 1998), producing a conditioning lesion (Richardson and Issa, 1984; Neumann and Woolf, 1999), or using microtransplants of sensory neurons (Davies et al., 1997). Little attention has been given however to the patterns of axonal growth once they have re-entered the CNS, either across a cut or after leaving a surrogate pathway. How far do they grow, does this growth follow normal or stereotypic routes, do they innervate

Received Sept. 1, 1999; revised Oct. 6, 1999; accepted Oct. 14, 1999.

This work was supported by the United States (Foundation Fighting Blindness), Spain (Fondo de Investigación Sanitaria 98/0341, Fundación Séneca Grant PB18FS97, and Ministerio de Educación y Cultura SAF97-0260-CE), and the European Union (Biomed Grant CT96-0976). We are grateful to Lidia Coll for technical assistance.

Correspondence should be addressed to Manuel Vidal-Sanz, Laboratorio de Oftalmología Experimental, Departamento de Oftalmología, Facultad de Medicina, Universidad de Murcia, E-30100 Espinardo, Murcia, Spain. E-mail: ofmmv01@ fcu.um.es.

Dr. Avilés-Trigueros's present address: Instituto de Bioingeniería, Departamento de Histología, Facultad de Medicina, Universidad Miguel Hernández, 03550 San Juan de Alicante, Alicante, Spain.

Copyright (C) 1999 Society for Neuroscience $\quad 0270-6474 / 99 / 200361-14 \$ 15.00 / 0$ and formed a different terminal arbor type within the stratum griseum superficiale. In the remaining two-thirds of the animals, retinal fibers formed a neuroma-like structure at the site of entry into the brainstem, or a few fibers extended for very short distances within the neighboring neuropil. These experiments suggest that regenerated retinal axons are capable of a highly selective reinnervation pattern within adult denervated retinorecipient nuclei in which they form well defined terminal arbors that may persist for long periods of time. In addition, these studies provide the anatomical correlate for our previous functional study on the re-establishment of the pupillary light reflex in this experimental paradigm.

Key words: peripheral nerve; axonal regeneration; retina; pretectal nuclei; superior colliculus; adult mammal

only regions that are their normal targets, or are they less specific in their patterns of terminal arborization?

One preparation well suited to investigate these questions is the primary optic pathway. If the optic nerve is sectioned intraorbitally and one end of a peripheral nerve (PN) segment is juxtaposed to the cut end, a small percentage of the retinal ganglion cell (RGC) population will consistently regenerate axons into it (Vidal-Sanz et al., 1987). If the opposite end of the PN graft is placed in the main retinorecipient target, the superior colliculus (SC), the regenerating axons will grow through the PN graft and extend for short distances into the targeted region to form synapses (Vidal-Sanz et al., 1987, 1991; Carter et al., 1989) that persist for long periods of time (Vidal-Sanz et al., 1991), are capable of driving postsynaptic cells (Keirstead et al., 1989; Sauvé et al., 1995), and mediating visually driven behaviors (Sasaki et al., 1996), including the pupillary light reflex (PLR) (Thanos, 1992; Whiteley et al., 1998). In the present study, we have asked how axons, allowed to enter the brainstem at different locations, might innervate the range of different nuclei with which they come into contact. Previous studies have shown that, when placed into retinorecipient regions (Vidal-Sanz et al., 1987, 1991; Carter et al., 1989, 1994; Thanos and Mey, 1995; Carter and Jhaveri, 1997; Thanos et al., 1997) or nonretinorecipient regions, such as the cerebellum (Zwimpfer et al., 1992), they can innervate it in a highly stereotypic manner. However, if presented with the possibility of growing through the brainstem to innervate normal retinorecipient or atypical targets, would they show selectivity of growth?

Functional studies on the restoration of the PLR by regenerat- 
ing retinal ganglion cell axons have been reported previously (Whiteley et al., 1998). Here, we provide a more detailed study of the morphology, development, and maintenance of the reestablished retinopretectal projections in those animals.

Part of this work has been published previously as a short communication (Avilés-Trigueros et al., 1997).

\section{MATERIALS AND METHODS}

Experiments were performed on adult female Sprague Dawley $(n=33)$ and PVG $(n=6)$ rats $(180-200 \mathrm{gm})$. Animal care and experimental procedures were performed in accordance with Home Office (UK) and European Union regulations, as well as National Institutes of Health guidelines.

Peripheral nerve grafting. Autologous segments of the left common peroneal nerve were used to link the retina with the brainstem following previously described methods (Vidal-Sanz et al., 1987). In brief, animals were deeply anesthetized using $7 \%$ chloral hydrate intraperitoneally (dissolved in saline, $0.42 \mathrm{mg} / \mathrm{gm}$ ). The optic nerve of the left eye was exposed intraorbitally, and after longitudinal incision of the meningeal sheath, the nerve was completely transected close to the sclera without affecting the retinal blood supply. One end of a 3-cm-long autologous common peroneal nerve segment was apposed to the ocular stump with three $10 / 0$ monofilament sutures. At the same time, the distal end of the PN segment was inserted into the ipsilateral side of the brainstem.

To investigate whether regrowing axons into the pretectum showed preferences for innervating retinorecipient nuclei, in 14 animals, the distal end of the PN graft was inserted into the superficial aspect of the midbrain, between the olivary pretectal nuclei (OPN) and the nucleus of the optic tract (NOT). In 19 additional rats, the pattern of extension of regenerated retinal axons along the midbrain and their capacity to innervate different pretectal nuclei were investigated by placing the distal end of the PN graft laterally in the diencephalon. To compare the above results with the growth pattern of regenerated retinal axons into their main retinorecipient target, the superior colliculus, in six additional Piebald Virol Glaxo (PVG) Brown Norway rats the distal end of the PN graft was inserted laterally into the superficial layers of the superior colliculus.

Because previous studies have suggested that intravitreal administration of tuftsin 1-3 increases the number of regenerating retinal ganglion cells (Thanos et al., 1993; Lawrence et al., 1996; Whiteley et al., 1998), 6 $\mu \mathrm{l}$ of tuftsin fragment 1-3 (Thr-Lys-Pro; Sigma, Poole, UK) $(2.5 \mu \mathrm{g} / \mathrm{ml}$ of PBS, pH 7.4) were injected intravitreally immediately after PN grafting.

To deprive the pretectum of normal visual input, the contralateral eye was removed. This also ensured that the normal optic input would not diminish the efficacy and specificity of the regenerated pathway (Radel et al., 1991). Many of the animals, whose anatomy is reported in detail in this manuscript, were used in a functional study to investigate reestablishment of the pupillary light reflex (Whiteley et al., 1998).

Tracer application and tissue processing. Regenerating retinal ganglion cell axons were identified with cholera toxin subunit B. At different time periods between 4 and 13 months after PN grafting, $5 \mu \mathrm{l}$ of $1 \%$ cholera toxin subunit B tracer (CTB) (List Biologic, Campbell, CA) (diluted in sterile distilled water) was injected into the vitreous chamber of the PN-grafted eye, with the aid of a $10 \mu$ l Hamilton microsyringe. Four days later, the rats were killed with an overdose of anesthesia and perfused transcardially with $0.9 \% \mathrm{NaCl}$ followed by $4 \%$ paraformaldehyde in 0.1 $\mathrm{M}$ phosphate buffer (PB), $\mathrm{pH} 7.4$, and their brains and distal end of the PN graft were carefully dissected out from the skull, post-fixed overnight in the same fixative at $4^{\circ} \mathrm{C}$, and cryoprotected by immersion in a solution of $30 \%$ sucrose in $\mathrm{PB}$ for $48 \mathrm{hr}$ at $4^{\circ} \mathrm{C}$. Brains were frozen in 2-methylbutane cooled in liquid nitrogen at $-60^{\circ} \mathrm{C}$, and $40-\mu \mathrm{m}$-thick serial coronal sections, from a level just rostral to the anterior commissure through the caudal tectum, were obtained on a freezing microtome.

Immunohistochemistry. Orthogradely transported CTB was immunolocalized using the protocol of Angelucci et al. (1996). In brief, frozen serial sections were washed in $\mathrm{PB}$, and endogenous peroxidase activity was blocked by soaking sections in $0.3 \%$ hydrogen peroxide in PB for 20 min. After rinsing in PB, sections were incubated for $30 \mathrm{~min}$ in $0.1 \mathrm{M}$ glycine in $\mathrm{PB}$ and then overnight at $4^{\circ} \mathrm{C}$ in $\mathrm{PB}$ containing $0.5 \%$ Triton $\mathrm{X}-100,4 \%$ normal rabbit serum (NRS) (Vector Laboratories, Burlingame, CA), and $2.5 \%$ bovine serum albumin (BSA) (Boehringer Mannheim, Mannheim, Germany). Sections were then incubated for $4 \mathrm{~d}$ at $4^{\circ} \mathrm{C}$ in a solution containing goat anti-CTB antibody (List Biologic) diluted 1:4000 in a PB solution containing $2 \%$ NRS, $2.5 \%$ BSA, and $2 \%$ Triton
$\mathrm{X}-100$. Binding of primary antibody was visualized by incubating in biotinylated rabbit anti-goat IgG antibody (Vector Laboratories) diluted 1:200 in $2 \%$ NRS, $2.5 \%$ BSA, and 2\% Triton X-100 in PB for $1 \mathrm{hr}$ at room temperature, followed by an incubation in avidin-biotin peroxidase complex (Vectastain ABC Kit Elite; Vector Laboratories) diluted 1:100 in PB for $1 \mathrm{hr}$; the peroxidase was detected using $0.025 \% 3,3^{\prime}$ diaminobenzidine tetrahydrochloride (Sigma) in PBS as a chromogen. After $5 \mathrm{~min}, 0.004 \% \mathrm{H}_{2} \mathrm{O}_{2}$ was added to the solution, and $3 \mathrm{~min}$ were allowed for development.

Tissue was thoroughly washed with PBS (four times for $15 \mathrm{~min}$ each) at $4^{\circ} \mathrm{C}$ and then mounted on chrome alum and gelatin-coated slides, air dried, counterstained with $0.1 \%$ bis-benzimide (Sigma), dehydrated in a series of alcohols, defatted in xylene, and coverslipped with DePeX.

Tissue examination. To investigate the course, distribution, and terminal arborization of regenerating retinal axons into the brainstem, sections were examined under bright field on a Zeiss (Oberkochen, Germany) microscope and/or a Leica (Nussloch, Germany) stereoscopic microscope. Sections containing CTB-labeled fibers were photographed, and drawings of axons and terminal arborizations were made from printed photographs and with the aid of a camera lucida attached to the Zeiss microscope. The orthograde tracing technique used in these studies is a sensitive method for identifying fine projections. This technique does not allow, however, full reconstruction of individual single arbors. Here, we present the morphology of the retinal axons and their branches as observed in the regions examined by light microscopy.

Because the insertion of the PN graft sometimes distorted the gross anatomy of the brainstem, it was often necessary to examine carefully coronal sections of the midbrain to identify the different nuclei of the brainstem. The use of the atlas of the rat brain (Paxinos and Watson, 1986) helped to identify the retinorecipient and nonretinorecipient nuclei of the brainstem. Serial coronal sections through the brainstem of control rats that had received intraocular injections of CTB, and were processed similarly, were used for comparison purposes.

\section{RESULTS}

In adult rats with peripheral nerve segments linking the retina with the brainstem, we have investigated axonal extension and reinnervation of retinorecipient nuclei within the pretectum (the OPN and the NOT) and the SC. The main findings of these anatomical studies can be summarized as follows. In approximately two-thirds of the experiments, regenerated axons failed to extend into the brainstem. In these, either axonal growth was curtailed at the end of the PN graft in a neuroma-like structure, or very few fibers were found, extending for minimal distances within the surrounding brainstem. In the remaining experiments, (1) retinal axons arriving at the lateral side of the brainstem can extend for distances of up to $6 \mathrm{~mm}$, running across the caudal diencephalon to the midline. Along their course within the diencephalon, axons targeted the main retinorecipient nuclei, the NOT and the OPN. Within these nuclei, retinal axons formed arborizations and showed varicosities and enlargements that resembled typical synaptic-like boutons. (2) Retinal axons entering at the dorsal aspect of the pretectum also extended for distances of $\sim 6 \mathrm{~mm}$ and arborized mainly within the NOT and OPN, indicating that there is a certain degree of specificity in their preferences for axonal extension and reinnervation. (3) Retinal axons arriving at the lateral aspect of the superior colliculus extended toward the superficial layers and formed typical terminal arbors. Thus, in general, the vast majority of regenerated retinal axons innervated and arborized into specific retinorecipient nuclei. (4) Some axons however, showed less directed growth, but these still failed to innervate nonvisual targets, even when they were partially denervated by the surgery.

\section{Gross anatomical findings}

In the 14 rats with the PN graft inserted adjacent to the OPN, the end of the graft was consistently found to enter the brainstem from above, most commonly somewhere between the anterior 
pretectal nucleus and the lateroposterior thalamic nucleus. In the 19 rats with the PN graft inserted more laterally into the diencephalon, the end of the graft was consistently found to enter the brainstem through the dorsolateral geniculate nucleus and the lateroposterior thalamic nucleus. Because the visual cortex was damaged making access to the brainstem, there was substantial atrophy of the dorsal lateral geniculate nucleus. In the six rats with the PN graft inserted laterally into the superior colliculus, the graft was consistently located in place. It did, however, transect the brachium of the inferior colliculus on its way to the medial geniculate, thus deafferenting this nucleus from its major sensory input.

Although for most of the sections examined under the microscope identification of retinorecipient and nonretinorecipient nuclei of the brainstem was obvious, in others the insertion of the PN graft into the brainstem caused a certain degree of anatomical distortion, with various degrees of neuropil bulging around the insertion site. Such anatomical distortion required careful examination of the coronal sections and consultation of the atlas of the brain (Paxinos and Watson, 1986) to identify anatomical structures.

There were important variations in the success of axonal regrowth into the brainstem. The results of the present study may be divided into three main groups, each of them consisting of approximately one-third of the animals. In one such group $(n=$ 11 ), we have observed a robust reinnervation of the pretectum or the superior colliculus. In the second group $(n=12)$, we have observed scarce innervation of the brainstem. The last group $(n=$ 16) consisted of animals that failed to show axonal invasion of the brainstem; instead, a neuroma-like formation was observed at the end of the PN graft.

\section{Neuroma-like formation}

In three animals with PN grafts inserted adjacent to the olivary pretectal nuclei (examined at 5, 7, and 12 months after PN grafting, respectively), in 11 animals with $\mathrm{PN}$ grafts inserted laterally to the midbrain [examined at $4(n=2), 5(n=2), 6(n=$ 1) (Fig. 1), $11(n=1), 12(n=3)$, and $13(n=2)$ months after $\mathrm{PN}$ grafting, respectively], and in two animals with PN grafts inserted laterally into the superior colliculus [(examined at $10(n=1)$ and $12(n=1)$ months after PN grafting, respectively], we observed no CTB-labeled fibers entering the brainstem. In these experiments, however, numerous CTB-labeled fibers were found within the end of the graft, in a neuroma-like ending (Fig. 1). Thus, not all axons that enter the peripheral nerve segment can re-enter the CNS, but they are often able to survive for considerable time periods. The presence of neuromas at the end of the PN graft appears to be related to poor reinnervation of the brainstem (Fig. 1).

\section{Scarce reinnervation of the brainstem}

In seven animals with PN grafts inserted adjacent to the olivary pretectal nuclei [examined at $5(n=1), 12(n=3)$, and $13(n=$ 3) months after PN grafting, respectively], in three rats with PN grafts inserted more laterally into the brainstem [examined at 4 $(n=1), 8(n=1)$, and $12(n=1)$ months after PN grafting, respectively] and in two rats with $\mathrm{PN}$ grafts inserted laterally into the SC [examined at $10(n=1)$ and $12(n=1)$ months after PN grafting, respectively], a few CTB-labeled fibers extended from the end of the PN graft into the brainstem for very short distances, within the vicinity of the end of the PN graft insertions, but did not innervate retinorecipient nuclei. These CTB-labeled axons showed neither arborizations nor terminal-like specializations.

\section{Robust reinnervation of the brainstem}

\section{Axonal extension through the brainstem and into} the pretectum

In contrast to the previous groups, in five rats with PN grafts inserted laterally into the brainstem [examined at $4(n=3)$ (Fig. $2), 8(n=1)$, and $13(n=1)$ months after PN grafting, respectively], a robust projection of CTB-labeled fibers extended from the end of the PN graft, through the dorsal aspect of the brainstem, toward the midline. Some of these fibers extended to the midline for distances of $\sim 6$ millimeters (Fig. 2). These fibers tended to arborize within the NOT first and then within the OPN. Within the NOT, CTB-labeled fibers formed a dense ramified mesh with numerous varicosities resembling bouton-like endings (Fig. 3). CTB-labeled fibers in the OPN formed less extensive arborizations but showed numerous ovoid swellings (bouton-like endings) within the fibers as they surrounded the OPN (Fig. 4). Some axons extended caudally to the SC in which they ran in the stratum griseum intermediale deep to the stratum opticum; these were never seen crossing the stratum opticum to attain the retinorecipient layers, nor was there evidence of terminal ramifications.

For one of these animals, drawings of all CTB-labeled fibers were obtained from every serial section, and samples of these drawings are presented in Figure 2. This figure illustrates the distribution of regenerated CTB-labeled fibers, as well as the extent of reinnervation within the pretectal region.

In animals with PN grafts introduced more rostrally, a group of axons was frequently labeled, which ran ventrolaterally in or adjacent to the internal medullary lamina. These could be traced to the zona incerta close to the substantia nigra, but no terminal arbor was ever seen associated with these fibers.

\section{Reinnervation of retinorecipient nuclei in the pretectum}

In four animals with the PN graft inserted on the dorsal aspect of the diencephalon between the OPN and NOT [examined at 4, 5, 7, and 11 (Fig. 5) months after PN grafting, respectively], large numbers of CTB-labeled fibers extended from the distal end of the PN graft into the pretectum and innervated extensively both the OPN and NOT. In some cases, a few isolated CTB-labeled fibers extended through the midline toward the contralateral OPN (Fig. 5). The technique used to identify regenerating retinal axons does not allow estimation of the number of axons growing into these nuclei, but Figures 2 and 5 illustrate individual examples of the robust reinnervation of the pretectum observed at two different time points after PN grafting, 16 and 46 weeks, respectively.

In general, CTB-labeled fibers followed the course of these pretectal nuclei, the OPN and NOT, and formed extensive terminal arborization and bouton-like structures within these nuclei. In these animals, as well as in the experiments with PN grafts inserted laterally into the brainstem, two main types of terminal arborization were observed. For the group of fibers innervating the NOT (Figs. 5, 6), CTB-labeled fibers formed a dense ramified mesh with numerous varicosities resembling bouton-like endings (Figs. 5, 6, 7A). CTB-labeled fibers on the OPN formed less extensive arborizations but showed numerous ovoid swellings within the fibers as they surround the OPN, resembling terminals en passant (Figs. 5, 6A, 7B). These terminal arborizations showed morphological characteristics, reminiscent of the terminal morphology of retinal axons in the retinorecipient pretectal nuclei, as observed with CTB in the hamster (Ling et al., 1998). In addition, other CTB-labeled regenerated fibers did not show terminal arborizations or bouton-like structures within these nuclei. 

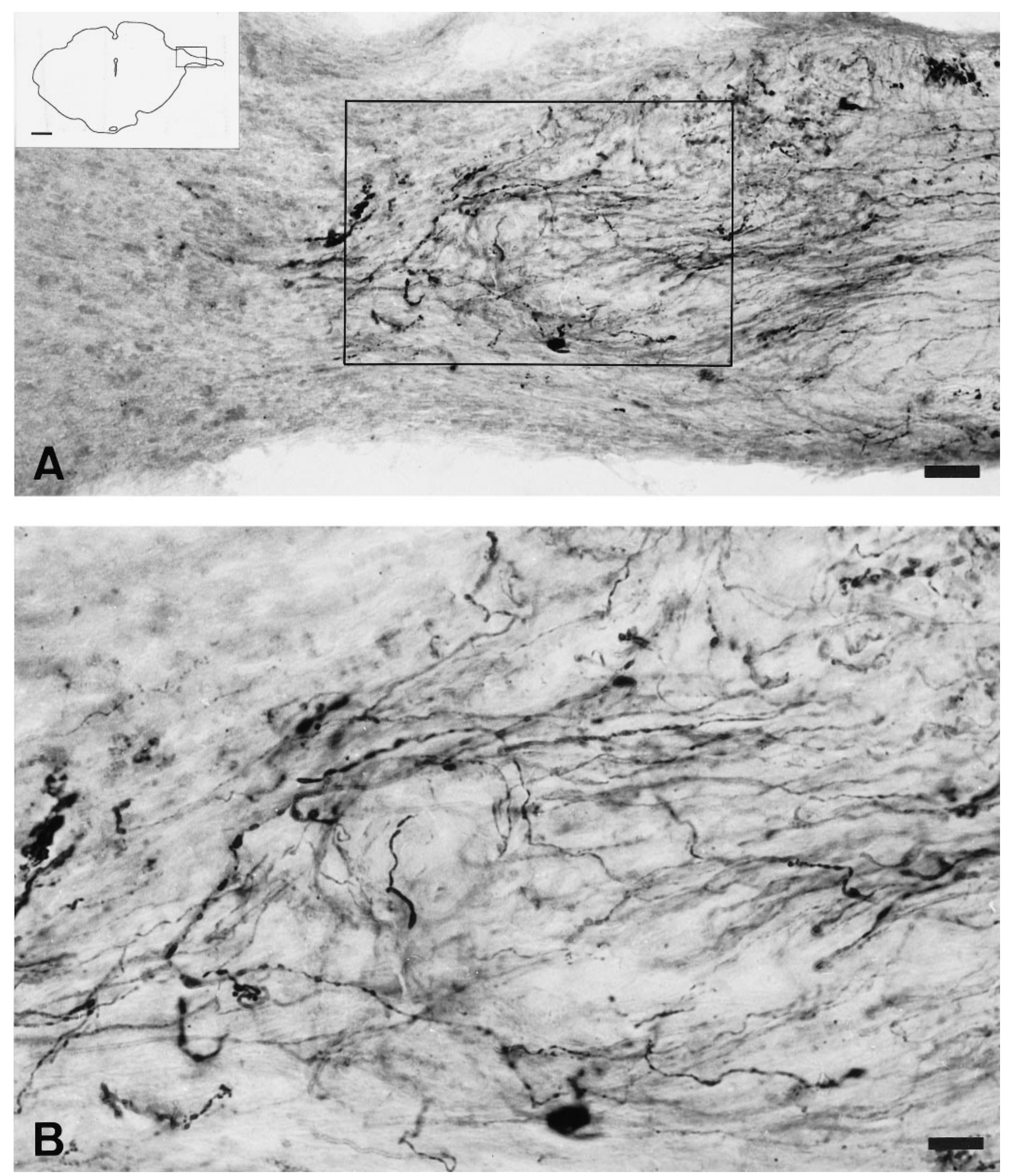

Figure 1. Light micrographs of a 40- $\mu$ m-thick cryostat coronal section illustrating retinal axons 24 weeks after connecting the left eye and the ipsilateral brainstem with a segment of peripheral nerve and $5 \mathrm{~d}$ after intraocular injection of CTB. $A$, Interface between PN graft and diencephalon. Most of the retinal axons do not exit the PN graft and appear within a neuroma-like formation. Scale bar, $47 \mu \mathrm{m}$. Inset is a drawing of the section, and the box indicates the region photographed. Scale bar, $1 \mathrm{~mm}$. $B$, Detail from box in $A$ showing CTB-labeled axons that reach the distal end of the PN segment but turn around and do not enter the brainstem. Scale bar, $19 \mu \mathrm{m}$. 


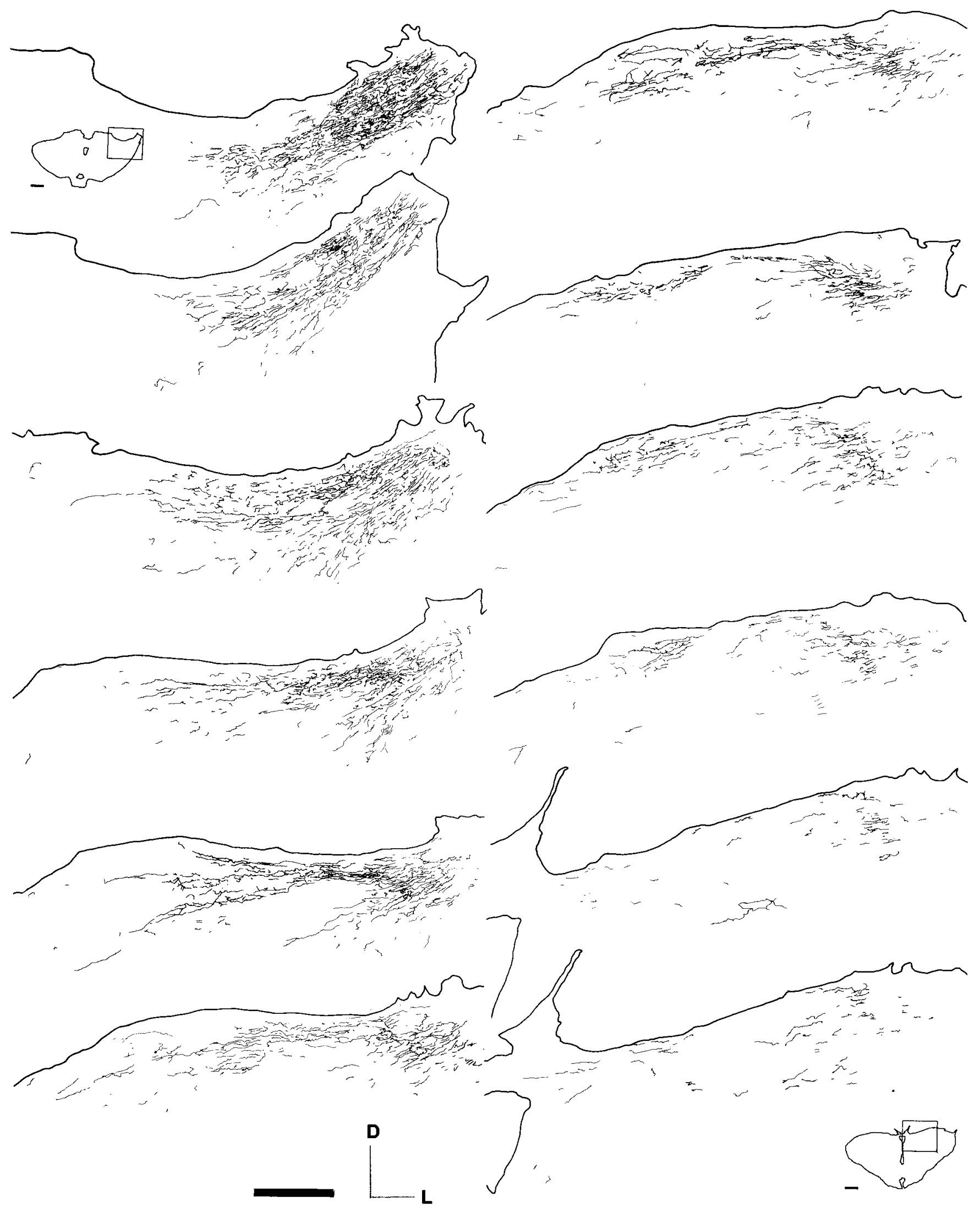

Figure 2. Drawings of alternate 40- $\mu$ m-thick cryostat coronal sections through the brainstem, from caudal (top left) to rostral (bottom right), of a rat 16 weeks after grafting a peripheral nerve segment between the left retina and the lateral aspect of the left diencephalon. The drawings illustrate the distribution of regenerated retinal fibers orthogradely labeled with CTB injected $5 \mathrm{~d}$ earlier into the PN-grafted retina. Note the extensive reinnervation through the pretectum. Scale bar, $0.5 \mathrm{~mm}$. The insets are drawings of the most caudal and rostral sections, respectively. Scale bar, $1 \mathrm{~mm}$. 

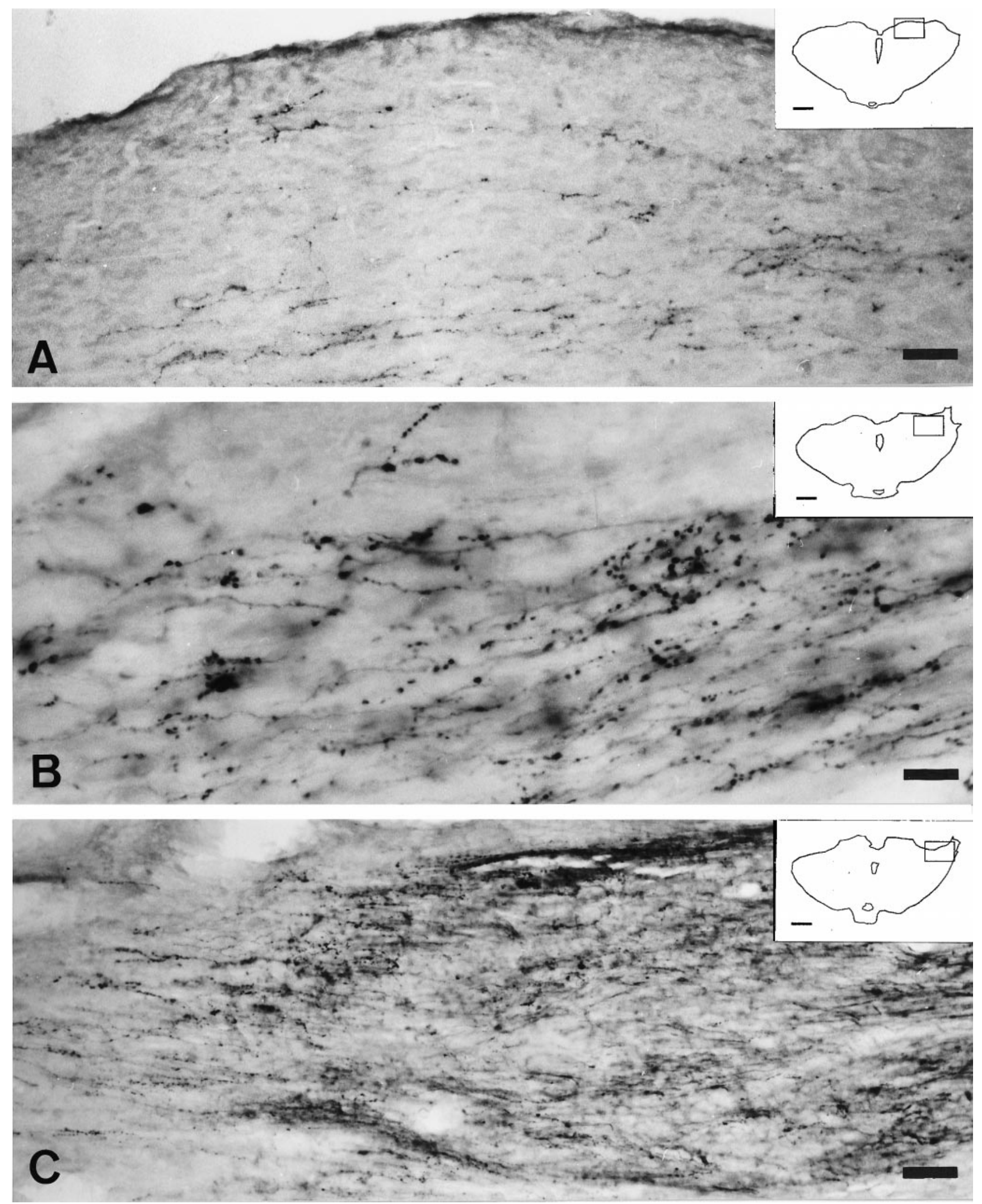

Figure 3. Light micrographs of $40-\mu \mathrm{m}$-thick cryostat coronal sections illustrating CTB-labeled retinal axons in the pretectum 16 weeks after grafting a segment of peripheral nerve between the left retina and the lateral side of the left diencephalon. $A$, CTB-labeled fibers extend through the dorsal aspect of the midbrain toward the midline. These fibers arborize within the NOT and OPN. Scale bar, $50 \mu \mathrm{m}$. $B$, CTB-labeled fibers show numerous varicosities within the NOT. Scale bar, $20 \mu \mathrm{m}$. $C$, PN graft entry zone lateral to the diencephalon. Note the interface between the PN graft and the midbrain and regenerated fibers crossing the interface. Scale bar, $50 \mu \mathrm{m}$. Insets in $A-C$ are drawings of the respective section of the midbrain, and the boxes indicate the region photographed. Scale bar, $1 \mathrm{~mm}$. 

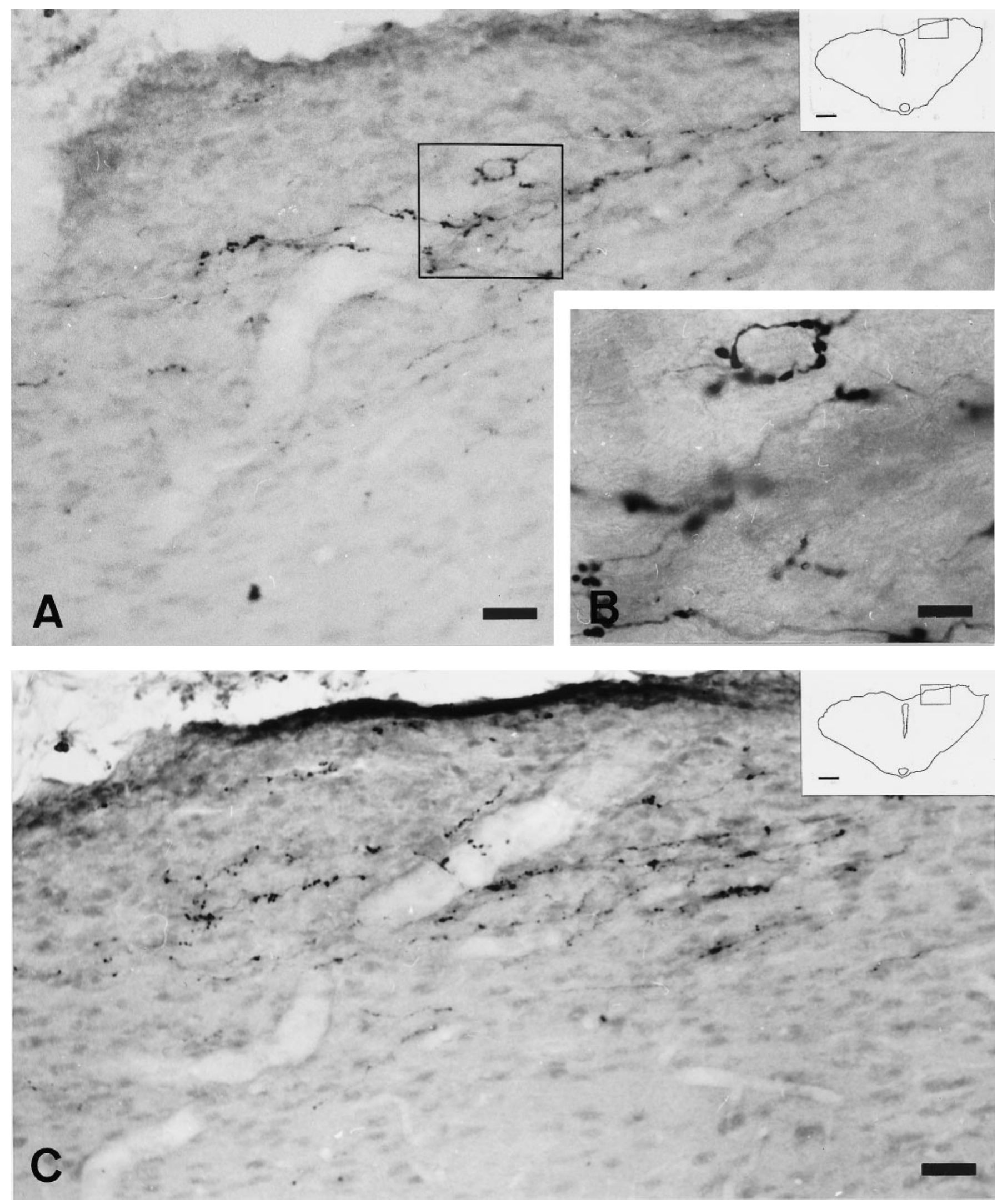

Figure 4. Light micrographs of 40- $\mu \mathrm{m}$-thick cryostat coronal sections illustrating CTB-labeled retinal axons in the region of the OPN 16 weeks after connecting the left eye and the lateral side of the left diencephalon by a segment of peripheral nerve. $A$, CTB-labeled fibers innervate the rostral limit of the OPN. Scale bar, $31 \mu \mathrm{m}$. $B$, Detail from $A$ showing a CTB-labeled axon with terminal varicosities in the OPN. Scale bar, $11 \mu \mathrm{m}$. $C$, Regenerated CTB-labeled fibers innervate the OPN and the rostral limit of the nucleus of the optic tract. Scale bar, $37 \mu \mathrm{m}$. Insets in $A$ and $C$ are drawings of the respective section of the midbrain, and the boxes indicate the region photographed. Scale bar, $1 \mathrm{~mm}$. 


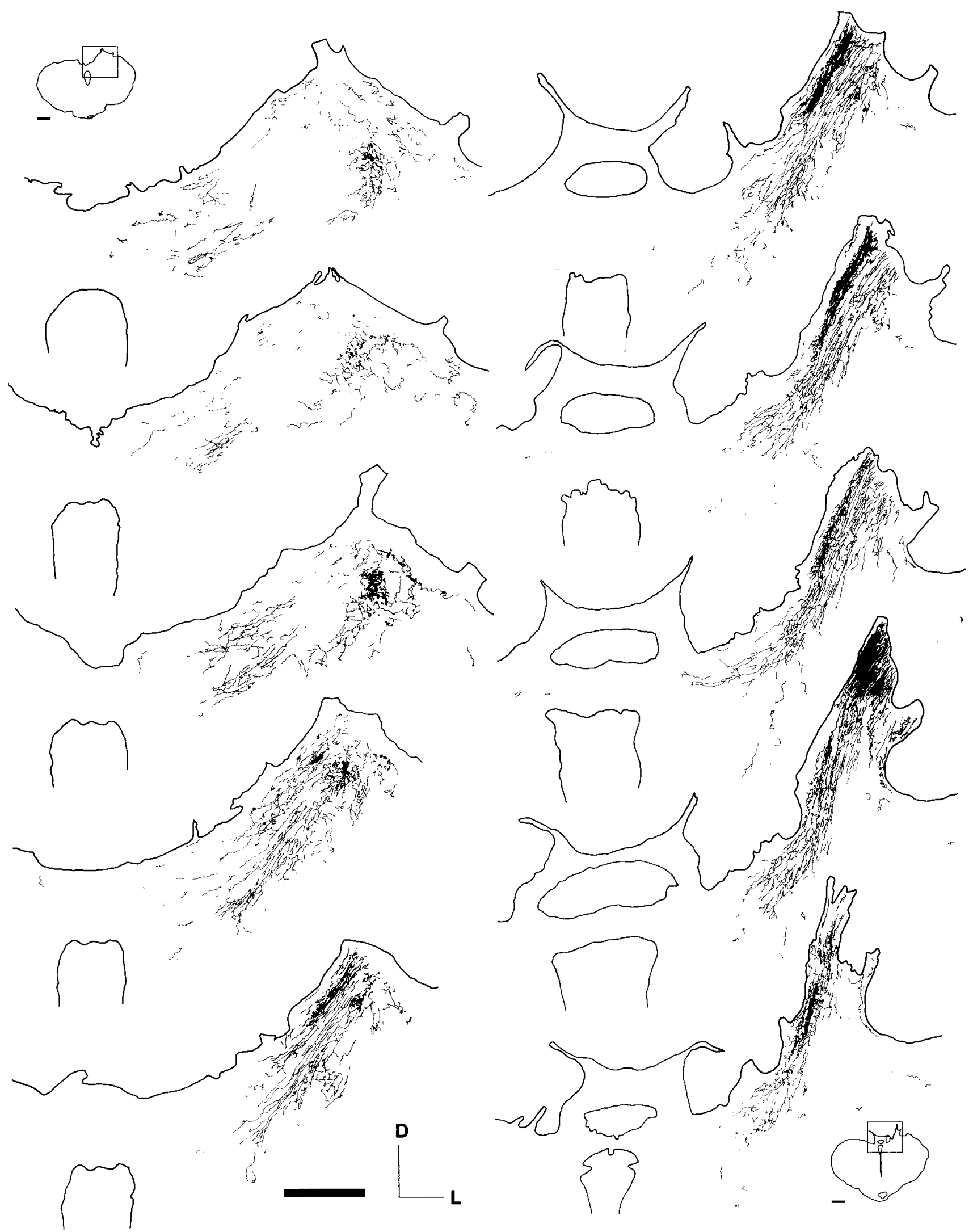

Figure 5. Drawings of consecutive 40- $\mu \mathrm{m}$-thick cryostat coronal sections through the brainstem, from caudal (top left) to rostral (bottom right), of a rat 46 weeks after grafting a peripheral nerve segment between the left retina and the dorsal aspect of the left midbrain between the OPN and NOT. The drawings illustrate the distribution of regenerated retinal fibers orthogradely labeled with CTB injected $5 \mathrm{~d}$ earlier into the PN-grafted retina. Note the segregation of the retinal axons between OPN and NOT from the rostral to the caudal aspect. Scale bar, $0.5 \mathrm{~mm}$. The insets are drawings of the most caudal and rostral sections, respectively. Scale bar, $1 \mathrm{~mm}$. 

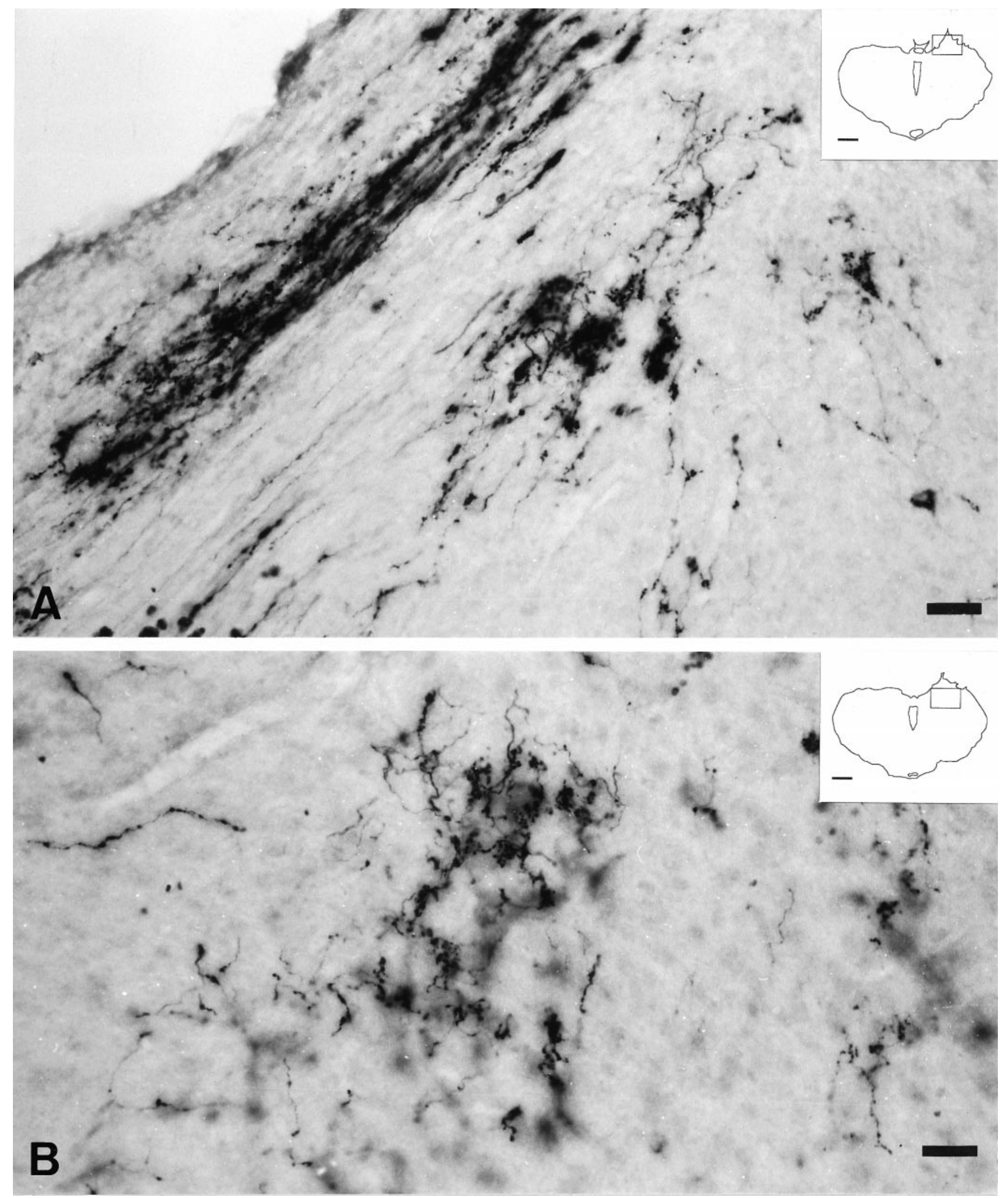

Figure 6. Light micrographs of $40-\mu \mathrm{m}$-thick cryostat coronal sections illustrating regenerated retinal fibers in the pretectum 46 weeks after grafting a segment of peripheral nerve between the left retina and the dorsal aspect of the left midbrain between the OPN and NOT and $5 \mathrm{~d}$ after intraocular injection of CTB. A, CTB-labeled retinal axons innervate the OPN extensively (toward the top left) and the rostral limit of the NOT (toward the middle and right). Scale bar, $35 \mu \mathrm{m} . B$, Extensive innervation of the NOT area with numerous varicosities resembling bouton-like endings in a more caudal section. Scale bar, $28 \mu \mathrm{m}$. Insets in $A$ and $B$ are drawings of the respective section of the midbrain, and the boxes indicate the region photographed. Scale bar, $1 \mathrm{~mm}$. 


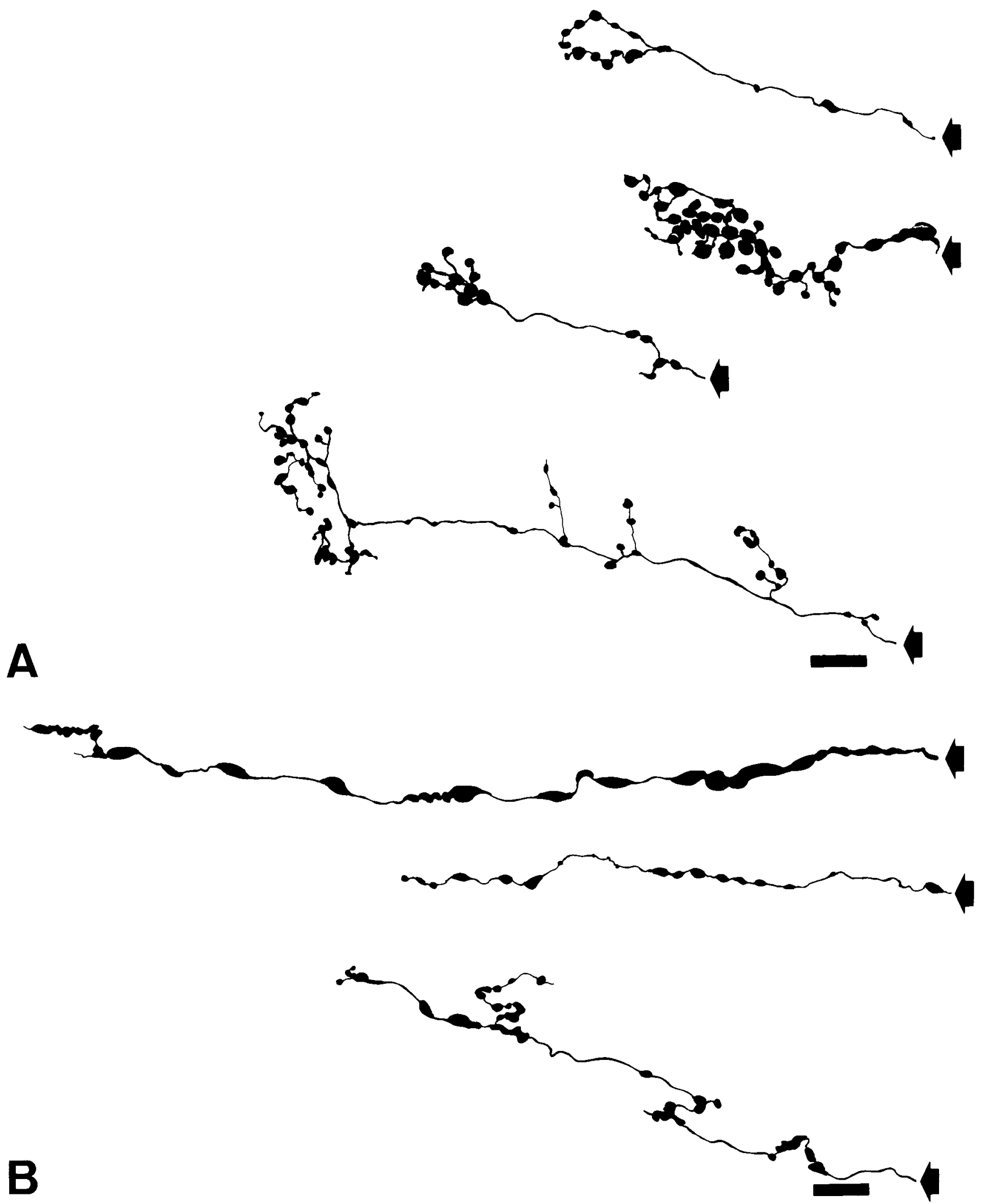

Figure 7. Drawings of retinal fibers 46 weeks after grafting a segment of peripheral nerve between the left retina and the dorsal aspect of the left midbrain between the OPN and NOT and $5 \mathrm{~d}$ after intraocular injection of CTB. $A$, Retinal fibers divide into fine branches decorated with numerous medium and small varicosities and terminal swellings, frequently forming rosette-like clusters. These fibers predominate in the NOT area. Scale bar, 9 $\mu \mathrm{m} . B$, Retinal fibers with little branching decorated with large elliptical varicosities along the length of the axon and with terminal swellings of different sizes. These fibers predominate in the OPN area and resemble en passant fibers. Scale bar, $9 \mu \mathrm{m}$. The stem axons are indicated by arrows. 


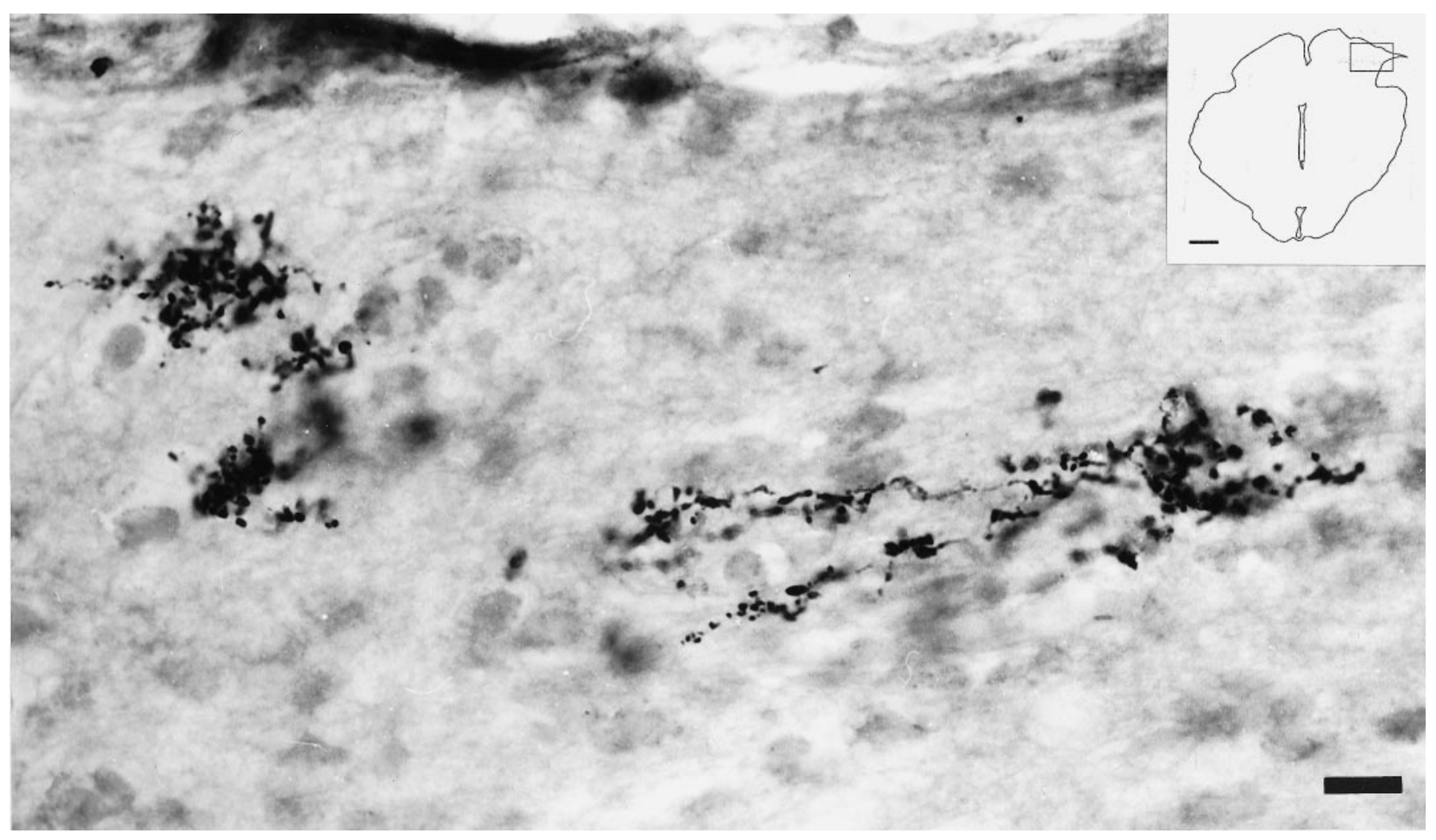

Figure 8. Light micrograph of a $40-\mu$ m-thick cryostat coronal section of the midbrain illustrating retinal fibers in the superficial gray 40 weeks after grafting a peripheral nerve segment between the left eye and the lateral aspect of the ipsilateral SC and $5 \mathrm{~d}$ after intraocular injection of CTB. Near the site of the PN graft entry, orthogradely labeled axons extend through the superficial layers of the SC forming typical arborizations. Note the high density of varicosities and terminal swellings resembling bouton-like endings on branching fibers. Scale bar, $17 \mu \mathrm{m}$. Inset illustrates a drawing of the section and indicates the region photographed. Scale bar, $1 \mathrm{~mm}$.

\section{Reinnervation of the superficial layers of the superior colliculus} In two rats with PN grafts inserted laterally into the superior colliculus [examined at $10(n=1)$ (Fig. 8$)$ and $12(n=1)$ (Fig. 9) months after PN grafting, respectively], large numbers of CTBlabeled axons extended for distances of up to $4 \mathrm{~mm}$ through the neuropil of the superficial gray area (SGS) and formed elaborated arborizations exhibiting numerous varicosities resembling bouton-like endings (Figs. 8, 9). Figure 9, $A$ and $B$, illustrates a single fiber observed within a single $40-\mu \mathrm{m}$-thick coronal section on the SGS of the SC showing branching points that bear multiple varicosities of similar appearance. These arborizations were similar to those observed in control rats (data not shown) and in normal hamsters (Mooney and Rhoades, 1990; Ling et al., 1998) but distinctively different from those observed in the pretectal region (Fig. 7). Thus, retinal axons were also capable of axonal extension through the superficial layers of the SC, although for smaller distances than in the brainstem before they arborize.

\section{DISCUSSION}

A previous study analyzed the functional characteristics of the recovered pupillary light reflex when regenerating retinal axons are directed toward the pretectal region of the brainstem (Whiteley et al., 1998). For the present studies, many of these animals, as well as a group in which the PN grafts were inserted into the colliculus, were used to investigate further the potential for extensive axonal regrowth and specificity of innervation within the brainstem, a region that contains several small (i.e., NOT and OPN) and large (i.e., the visual layers of the SC) retinorecipient nuclei. We have used the neuroanatomical tracer CTB, taking advantage of a methodology (Angelucci et al., 1996; Ling et al., 1998) that demonstrates axons with greater sensitivity than techniques used in most previous regeneration studies.

\section{Neuroma-like formation at the PNS-CNS interface}

One-third of the animals analyzed showed numerous CTBlabeled axons that failed to leave the graft, being confined to a neuroma-like formation at the interface between the graft and brainstem. We have not investigated the cause of the formation of the neuroma-like endings, the glial reactions that might be associated with the lack of axonal penetration into the midbrain, or the presence of inhibitory molecules, which may also be responsible for the curtailed growth observed in these instances and which are known to be expressed in the damaged CNS (Dusart et al., 1999) and at the PNS-CNS interface (Liuzzi and Lasek, 1987; Bandtlow et al., 1990; Smith et al., 1990; Davies et al., 1997, 1999; Fawcett, 1997). Although it is interesting that these axons survived for prolonged periods without contact with a target, it is not clear whether these axons might represent the small percentage that survive axotomy (Villegas-Pérez et al., 1993) or whether they are being protected by the neuroma-like environment or by that provided by the nerve graft.

\section{Extensive axonal regrowth within the brainstem}

In an additional one-third of the animals, regenerated axons entered the brain, extending for distances of up to $\sim 6 \mathrm{~mm}$. Extensive axonal ingrowth has been reported by others using a 

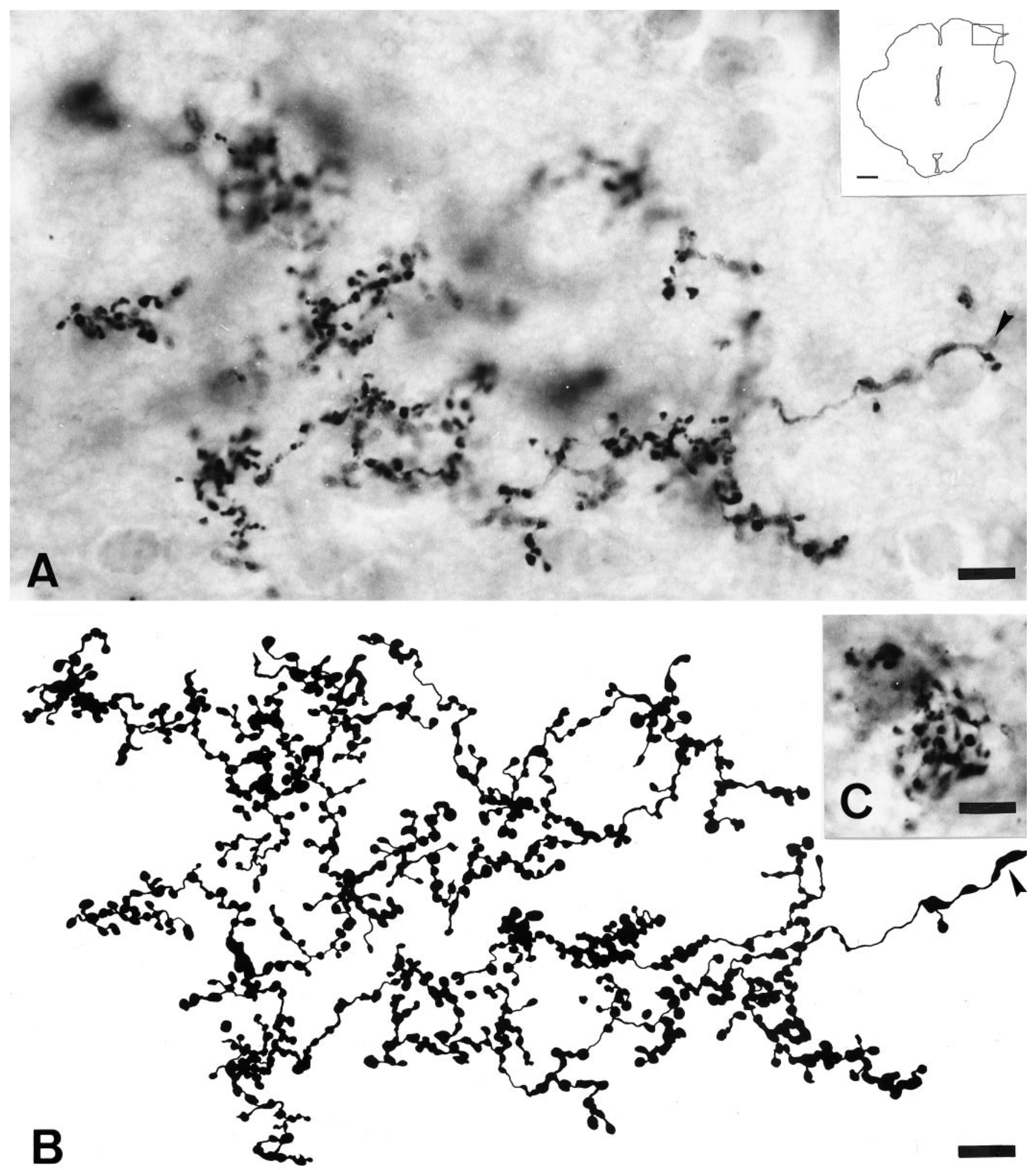

Figure 9. Light micrographs and drawing illustrating regenerated retinal fibers in the stratum griseum superficiale of 40- $\mu \mathrm{m}$-thick cryostat sections of the midbrain 48 weeks after grafting a segment of PN between the left eye and the lateral side of the ipsilateral SC and $5 \mathrm{~d}$ after intraocular injection of CTB. A, Single regenerated RGC axon in the SGS of the SC forming many branches that bear multiple varicosities of similar appearance and uniform size. Scale bar, $10 \mu \mathrm{m}$. Inset illustrates a drawing of the midbrain section and indicates the region photographed. Scale bar, $1 \mathrm{~mm}$. The stem axon is indicated by an arrowhead. $B$, High-power reconstruction of the terminal arbor in $A$. Scale bar, $9 \mu \mathrm{m}$. $C$, Close interrelation between terminal cluster of bouton-like endings of regenerated retinal projections and SC neurons. Scale bar, $8 \mu \mathrm{m}$. 
variety of experimental strategies to circumvent the inhibitory properties of the mature CNS (Caroni and Schwab, 1988; McKerracher et al., 1994), such as transplants of olfactory ensheathing cells (Li et al., 1997, Ramón-Cueto et al., 1998), activated macrophages (Lazarov-Spiegler et al., 1996), or introducing trophic factors (Cheng et al., 1996; Menei et al., 1998) or antibodies against growth-inhibitory molecules present in the mature brain (Schnell and Schwab., 1990; Z'Graggen et al., 1998). However, the lengthy regrowth within the CNS of intrinsic damaged fibers without the use of a surrogate pathway or addition of growthpromoting factors as observed here has not been reported previously. Furthermore, the observation of large numbers of axons reinnervating the brainstem (Figs. 2, 5) might suggest that this capacity for extensive axonal re-elongation within the brainstem may be present for many of the retinal fibers that regenerate into the PN graft. It is noteworthy here that long axonal growth is through the relatively myelin-poor dorsal brainstem or adjacent to the internal medullary lamina. Although axons in the dorsal brainstem were observed deep to the myelin-rich stratum opticum of the superior colliculus, these did not cross it to enter the superficial retinorecipient layers.

\section{Specific reinnervation of retinorecipient nuclei}

In the classical nerve graft reinnervation paradigm (Vidal-Sanz et al., 1987), the distal segment was placed close to the target being innervated (Vidal-Sanz et al., 1987, 1991; Carter et al., 1989, 1994). This was replicated in the present study in the series of grafts inserted in the SC. Accordingly, innervation was specific for the SGS, the normal target of most optic axons (Lund, 1969; Linden and Perry, 1983). Extraneous projections to other sites were not seen. Following the same principle, the first set of grafts to the prectectum were also inserted close to these nuclei, although because the nuclei are more compact than the colliculus, they normally entered the brainstem in the close vicinity rather than directly into the nuclei. Under such circumstances, some axons were seen crossing the midline to innervate the contralateral nucleus (Fig. 2). This led us to insert the nerves some distance from the nuclei. Behaviorally, this gave no significant difference from grafts inserted closer to the pretectum (Whiteley et al., 1998), and anatomically we found that axons, although coursing for long distances through the brainstem, still showed selectivity for optic target regions. This occurred although some nuclei within their trajectory were deafferented by the surgery associated with graft insertion.

The specificity of innervation of visual and nonvisual targets would appear to be at odds with the observation of Zwimpfer et al. (1992) showing innervation of the cerebellum by optic axons regenerating through peripheral nerve grafts. There is, however, a significant difference in experimental design in that, in the present study, the axons have a "choice" of optic or nonoptic targets, whereas in the cerebellum study, no choice is available. We do not know, however, whether there is transient innervation of nonoptic sites as happens in normal development (Frost, 1986), because in this study we focussed on longer survival times. We do know, however, that axons that are routed in totally anomalous directions, such as toward the zona incerta, failed to show evidence of terminal ramifications.

\section{Target-specific terminal arbor morphology}

Our results suggest that regenerated retinal axons adopt distinctive patterns of terminal arborizations depending on the target they reinnervate. For instance, whereas axons entering the OPN showed little ramification and swellings reminiscent of the typical retinal innervation of this nucleus, the NOT axons tended to show more profuse ramifications and arborizations with terminal swellings. Furthermore, these types of terminals are reminiscent of the terminals previously described for such retinorecipient nuclei in another rodent (Ling et al., 1998). Within this context, what is also remarkable is the similarity of the morphology of the elaborate arborizations found in the superficial layers of the superior colliculus (Figs. 8, 9) with that described in normal animals (Ling et al., 1998). This indicates further specificity of terminal arborization within the retinorecipient reinnervated target. Thus, it appears that the morphology of the arborization is dictated by the recipient region more than by the type of retinal fiber arriving to target (Carter and Jhaveri, 1997) and that axons modify their arbors to adapt to the local conditions of the target nucleus.

\section{Scarce innervation of the brainstem}

In the remaining one-third of the animals, there was poor outgrowth of axons out of the PN graft into the surrounding midbrain. These few axons extended for very limited distances and did not show evidence of terminal aborizations. Although these observations are more difficult to understand, it is possible that the lack of axonal extension and arbor formation relates to their inability to reach retinorecipient nuclei. Alternatively, because a large proportion of the animals in this group of experiments were analyzed after long time intervals, it is conceivable that with time, as has been suggested previously, there is degeneration of regenerated axons (Keirstead et al., 1985; Whiteley et al., 1998) or the parent cell bodies (Villegas-Pérez et al., 1988, 1993; Thanos and Mey, 1995). If this were to be the case, this group of experiments could account for the group of animals that showed major deterioration of their pupillary light responses with time, both in their amplitude and latency (Whiteley et al., 1998).

\section{Long-term reinnervation of the retinorecipient nuclei}

In the functional study of the recovered pupillary light reflex (Whiteley et al., 1998), although some of the animals had responses to light that persisted for up to 15 months after PN grafting, others deteriorated with time. For instance, approximately one-half of the animals that showed a PLR early after PN grafting retained measurable responses at later time points, between 7 and 11 months. One possible explanation suggested at the time was that perhaps there was a concomitant loss of regenerated axons. The present anatomical study shows that a robust innervation of the OPN at later time points was present only in approximately the same proportion of animals (approximately half of the responders in the functional study); thus, it is tempting to speculate that indeed not all the axons that succeeded in making functional synaptic contacts with a retinorecipient target (the OPN) at some point have their long-term survival ensured. The reasons for this axonal withdraw are unknown.

The results are encouraging for any study in which regeneration of severed axons has been achieved. Once they have traversed the lesion site, optic axons can grow unaided for considerable distances into the host neuropil, and most important, they clearly show specificity of innervation, although the molecular environment available to them, including levels of growth factors, inhibitory factors, and substrate molecules, are very different from those encountered by the same pathway during development.

\section{REFERENCES}

Angelucci A, Clasca F, Sur M (1996) Anterograde axonal tracing with the subunit B of the cholera toxin: a highly sensitive immunohistochem- 
ical protocol for revealing fine axonal morphology in adult and neonatal brains. J Neurosci Methods 65:101-112.

Avilés-Trigueros M, Sauvé Y, Villegas-Pérez MP, Warton S, Lund RD, Vidal-Sanz M (1997) Retinal ganglion cell axonal regrowth into the pretectum of adult rats with restored pupillary light reflex. Soc Neurosci Abstr 23:1992.

Bandtlow C, Zachleder T, Schwab ME (1990) Oligodendrocytes arrest neurite growth by contact inhibition. J Neurosci 10:3837-3848.

Caroni P, Schwab ME (1988) Antibody against myelin-associated inhibitor of neurite growth neutralises non-permissive substrate properties of CNS white matter. Neuron 1:85-96.

Carter D, Bray GM, Aguayo AJ (1989) Regenerated retinal ganglion cell axons can form well-differentiated synapses in the superior colliculus of adult hamsters. J Neurosci 9:4042-4050.

Carter D, Bray GM, Aguayo AJ (1994) Long-term growth and remodeling of regenerated retino-collicular connections in adult hamsters. J Neurosci 14:590-598.

Carter DA, Jhaveri S (1997) Retino-geniculate axons regenerating in adult hamsters are able to form morphologically distinct terminals. Exp Neurol 146:315-322.

Cheng H, Cao Y, Olson L (1996) Spinal cord repair in adult paraplegic rats: partial restoration of hind limb function. Science 273:510-513.

David S, Aguayo AJ (1981) Axonal elongation into peripheral nervous system "bridges" after central nervous system injury in adult rats. Science 214:931-933.

Davies SJA, Fitch MT, Memberg SP, Hall AK, Raisman G, Silver J (1997) Regeneration of adult axons in white matter tracts of the central nervous system. Nature 390:680-684.

Davies SJA, Goucher DR, Doller C, Silver J (1999) Robust regeneration of adult sensory axons in degenerating white matter of the adult rat spinal cord. J Neurosci 19:5810-5822.

Dusart I, Morel MP, Wehrle R, Sotelo C (1999) Late axonal sprouting of injured Purkinje cells and its temporal correlation with permissive changes in the glial scar. J Comp Neurol 408:399-418.

Fawcett JW (1997) Astrocytic and neuronal factors affecting axon regeneration in the damaged central nervous system. Cell Tissue Res 290:371-377.

Frost DO (1986) Development of anomalous retinal projections to nonvisual thalamic nuclei in Syrian hamsters: a quantitative study. J Comp Neurol 252:95-105.

Keirstead SA, Rasminsky M, Fukuda Y, Carter DA, Aguayo AJ, VidalSanz M (1989) Electrophysiologic responses in hamster superior colliculus evoked by regenerating retinal axons. Science 246:255-257.

Lawrence JM, Lawson DDA, Whiteley SJO, Lund RD, Sauvé Y (1996) Effect of Schwann cells and macrophage inhibitory factor (MIF) on the survival of rat retinal ganglion cells (RGCs) after axotomy and peripheral nerve (PN) grafting. Soc Neurosci Abstr 22:320.

Lazarov-Spiegler O, Solomon AS, Zeev-Brann AB, Hirschberg DL, Lavie V, Schwartz M (1996) Transplantation of activated macrophages overcomes central nervous system regrowth failure. FASEB J 10:1296-1302.

Lazarov-Spiegler O, Solomon AS, Schwartz M (1998) Peripheral nervestimulated macrophages simulate a peripheral nerve-like regenerative response in rat transected optic nerve. Glia 24:329-337.

Li Y, Field PM, Raisman G (1997) Repair of adult corticospinal tract by transplants of olfactory ensheathing cells. Science 277:2000-2002.

Linden R, Perry VH (1983) Massive retinotectal projection in rats. Brain Res 272:145-149.

Ling C, Schneider GE, Jhaveri S (1998) Target-specific morphology of retinal axon arbors in the adult hamster. Vis Neurosci 15:559-579.

Liuzzi FJ, Lasek RJ (1987) Astrocytes block axonal regeneration in mammals by activating the physiological stop pathway. Science 237:642-645.

Lund RD (1969) Synaptic patterns of the superficial layers of the superior colliculus of the rat. J Comp Neurol 135:179-208.

McKerracher L, David S, Jackson DL, Kottis V, Dunn RJ, Braun PE (1994) Identification of myelin-associated glycoprotein as a major myelin-derived inhibitor of neurite growth. Neuron 13:805-811.

Menei P, Montero-Menei C, Whittemore SR, Bunge RP, Bunge MB (1998) Schwann cells genetically modified to secrete human BDNF promote enhanced axonal regrowth across transected adult rat spinal cord. Eur J Neurosci 10:607-621.
Mooney RD, Rhoades RW (1990) Relationships between physiological and morphological properties of retinocollicular axons in the hamster. J Neurosci 10:3164-3177.

Neumann S, Woolf CJ (1999) Regeneration of dorsal column fibers into and beyond the lesions site following adult spinal cord injury. Neuron 23:83-91.

Paxinos G, Watson C (1986) The rat brain in stereotaxic coordinates. New York: Academic.

Radel JD, Kustra DJ, Lund RD (1991) Rapid enhancement of transplant-mediated pupilloconstriction after elimination of competing host optic input. Dev Brain Res 60:275-278.

Ramón-Cueto A, Plant GW, Avila J, Bunge MB (1998) Long-distance axonal regeneration in the transected adult rat spinal cord is promoted by olfactory ensheathing glia transplants. J Neurosci 18:3803-3815.

Richardson P, Issa VM (1984) Peripheral injury enhances regeneration of primary sensory neurones. Nature 309:791-793.

Sasaki H, Coffey P, Villegas-Pérez MP, Vidal-Sanz M, Young M, Lund RD, Fukuda Y (1996) Light induced EEG desynchronization and behavioral arousal in rats with restored retinocollicular projection by peripheral nerve graft. Neurosci Lett 218:45-48.

Sauvé Y, Sawai H, Rasminsky M (1995) Functional synaptic connections made by regenerated retinal ganglion cell axons in the superior colliculus of adult hamsters. J Neurosci 15:665-675.

Schnell L, Schwab ME (1990) Axonal regeneration in the rat spinal cord produced by an antibody against myelin-associated neurite growth inhibitors. Nature 343:269-272.

Smith GM, Rutishauser U, Silver J, Miller RH (1990) Maturation of astrocytes in vitro alters the extent and molecular basis of neurite outgrowth. Dev Biol 138:377-390.

Thanos S (1992) Adult retinofugal axons regenerating through peripheral nerve grafts can restore the light-induced pupilloconstriction reflex. Eur J Neurosci 4:691-699.

Thanos S, Mey J (1995) Type-specific stabilization and target-dependent survival of regenerating ganglion cells in the retina of adult rats. J Neurosci 15:1057-1079.

Thanos S, Mey J, Wild M (1993) Treatment of the adult retina with microglia-suppressing factors retards axotomy-induced neuronal degradation and enhances axonal regeneration in vivo and in vitro. J Neurosci 13:455-466.

Thanos S, Naskar R, Heiduschka P (1997) Regenerating ganglion cell axons in the adult rat establish retinofugal topography and restore visual function. Exp Brain Res 114:483-491.

Vidal-Sanz M, Bray GM, Villegas-Pérez MP, Thanos S, Aguayo AJ (1987) Axonal regeneration and synapse formation in the superior colliculus by retinal ganglion cells in the adult rat. J Neurosci 9:2894-2909.

Vidal-Sanz M, Bray GM, Aguayo AJ (1991) Regenerated synapses persist in the superior colliculus after the regrowth of retinal ganglion cell axons. J Neurocytol 20:940-952.

Villegas-Pérez MP, Vidal-Sanz M, Bray GM, Aguayo AJ (1988) Influences of peripheral nerve grafts on the survival and regrowth of axotomized retinal ganglion cells in adult rats. J Neurosci 8:265-280.

Villegas-Pérez MP, Vidal-Sanz M, Rasminsky M, Bray GM, Aguayo AJ (1993) Rapid and protracted phases of retinal ganglion cell loss follow axotomy in the optic nerve of adult rats. J Neurobiol 24:23-36.

Whiteley SJO, Avilés-Trigueros M, Sauvé Y, Vidal-Sanz M, Lund RD (1998) Extent and duration of recovered pupillary light reflex following retinal ganglion cell axon regeneration through peripheral nerve grafts directed to the pretectum in adult rats. Exp Neurol 154:560-572.

Xu XM, Zhang SX, Li H, Aebisher P, Bunge MB (1999) Regrowth of axons into the distal spinal cord through a Schwann-cell-seeded minichannel implanted into hemisected adult rat spinal cord. Eur J Neurosci 11:1723-1740.

Z'Graggen WJ, Metz GA, Kartje GL, Thallmair M, Schwab ME (1998) Functional recovery and enhanced corticofugal plasticity after unilateral pyramidal tract lesion and blockade of myelin-associated neurite growth inhibitors in adult rats. J Neurosci 18:4744-4757.

Zwimpfer T, Aguayo AJ, Bray GM (1992) Synapse formation and preferential distribution in the granule cell layer by regenerating retinal ganglion cell axons guided to the cerebellum of adult hamsters. J Neurosci 12:1144-1159. 